\title{
Phase I/II study to assess the clinical pharmacology and safety of single ascending and multiple subcutaneous doses of PF-06881894 in women with non-distantly metastatic breast cancer
}

\author{
Hsuan-Ming Yao ${ }^{1}$ D $\cdot$ Sarah Ruta Jones ${ }^{2} \cdot$ Serafin Morales $^{3} \cdot$ Shahrzad Moosavi $^{4} \cdot$ Jeffrey Zhang $^{1} \cdot$ Amy $^{\text {Freyman }}{ }^{5}$. \\ Faith D. Ottery ${ }^{6}$
}

Received: 6 April 2021 / Accepted: 6 September 2021 / Published online: 7 October 2021

(c) The Author(s) 2021

\begin{abstract}
Purpose To evaluate the pharmacodynamics (PD), pharmacokinetics (PK), and safety of single and multiple doses of PF-06881894 (pegfilgrastim-apgf; Nyvepria ${ }^{\mathrm{TM}}$ ), a biosimilar to reference pegfilgrastim (Neulasta ${ }^{\circledR}$ ), in women with nondistantly metastatic breast cancer.

Methods In Phase I (Cycle 0) of this Phase I/II study, the PD response (absolute neutrophil count [ANC]; CD34 + count), PK profile, and safety of a single 3- or 6-mg subcutaneous dose of PF-06881894 were assessed in chemotherapy-naïve patients before definitive breast surgery. In Phase II (Cycles 1-4), the PD response (duration of severe neutropenia [DSN, Cycle 1], ANC [Cycles 1 and 4]) and PK profile (Cycles 1 and 4) of single and multiple 6-mg doses of PF-06881894 concomitant with chemotherapy and after definitive breast surgery were assessed.

Results Twenty-five patients (mean age 59 years) were enrolled (Cycle $0, n=12$; Cycles $1-4, n=13$ ). In Cycle 0 , PD responses and PK values were lower with 3-mg versus 6-mg PF-06881894. In Cycles 1 and 4, mean DSN was 0.667 days after single or multiple 6-mg doses of PF-06881894, respectively. In Cycle 4 versus Cycle 1, PD responses were more robust; PK values (mean area under the curve, maximum concentration) were lower; and clearance values were higher. The safety profile of PF-06881894 was similar to that for reference pegfilgrastim.

Conclusion PF-06881894 as a single 3- or 6-mg dose prior to definitive surgery, or multiple 6-mg/cycle doses postoperatively, with/without myelosuppressive chemotherapy, was consistent with the clinical pharmacology and safety profile of reference pegfilgrastim.
\end{abstract}

Trial registration October 2017. ClinicalTrials.gov Identifier: NCT02650193. EudraCT Number: 2015-002057-35.

Keywords Biosimilar $\cdot$ Breast cancer $\cdot$ Chemotherapy $\cdot$ Neutropenia $\cdot$ Pegfilgrastim $\cdot$ Myelosuppression

\section{Introduction}

Hsuan-Ming Yao

hsuan-ming.yao@pfizer.com

1 Pfizer Inc, Lake Forest, IL, USA

2 Clinical Development and Operations, Pfizer Inc, Collegeville, PA, USA

3 Hospital Universitario Arnau de Vilanova, Lleida, Spain

4 Pfizer Inc, New York, NY, USA

5 Pfizer Inc, Cambridge, MA, USA

6 Ottery \& Associates LLC, Deerfield, IL, USA
Myelosuppressive chemotherapy is a clinically important iatrogenic cause of febrile neutropenia, with chemotherapyinduced complications of neutropenia largely contributing to dose-limiting toxicity (DLT) [1]. Severe neutropenia and febrile neutropenia can prevent the completion of targeted therapy via delays in treatment, dose reductions, and discontinuations of chemotherapy. DLT can also cause a patient to be unable to complete chemotherapy without undue Grade 3 or 4 therapeutic toxicity [2,3], potentially compromising long-term survival.

In addition to the myelotoxicity of many chemotherapeutic regimens, patient risk factors for myelosuppression (age $>65$ years, persistent neutropenia, liver or renal 
dysfunction) and disease characteristics (bone, bladder, and pancreatic cancers) can affect the risk of developing febrile neutropenia [4-6]. The prophylactic use of granulocyte colony-stimulating factors (G-CSF) is therefore recommended for patients at high $(>20 \%)$ or intermediate (10-20\%) risk of febrile neutropenia to reduce the risk of severe, potentially life-threatening infections and hospitalization [1,7-10].

Endogenous G-CSFs are the primary cytokines regulating the activation, proliferation, differentiation, maturation, and survival of neutrophil precursor cells in bone marrow, as well as mature neutrophil cell function. During antineoplastic therapy (chemotherapy, radiotherapy, or chemoradiotherapy), endogenous G-CSF can be inadequate to counteract myelosuppression [11]. In the context of chemotherapy, a neutrophil nadir is often reached within 7 days post-administration [12, 13]. Limiting nadir depth and duration can help minimize the development and incidence of subsequent neutropenic complications and limit chemotherapy dose reductions or delays [14].

PF-06881894 (pegfilgrastim-apgf; Nyvepria ${ }^{\mathrm{TM}}$, Pfizer, NY, USA), a pegylated version of endogenous G-CSF, has been approved by the US Food and Drug Administration (FDA), Health Canada, and European Medicines Agency as a biosimilar to reference pegfilgrastim (Neulasta ${ }^{\circledR}$, Amgen Inc, Thousand Oaks, CA, USA) [15, 16]. Biosimilars are versions of already licensed reference medicines, with highly similar physicochemical and biological characteristics and no clinically meaningful differences in terms of safety, purity, and potency [17]. Pegfilgrastim-apgf treatment is indicated to decrease the incidence of infection, as manifested by febrile neutropenia, in patients with non-myeloid cancers who receive myelosuppressive anticancer drugs associated with a clinically significant incidence of febrile neutropenia [16]. PEGylation, the addition of polyethylene glycol (PEG) to a protein, prolongs the circulating halflife compared with the non-pegylated protein. PEGylation for pegfilgrastim-apgf consists of the addition of a $20 \mathrm{kDa}$ monomethoxy-polyethylene glycol polymer moiety [18]. As a result, the required G-CSF dosing schedule may be decreased from once-daily filgrastim to once-per-chemotherapy cycle pegfilgrastim. This simplifies G-CSF use and supports achievement of target dose intensity of chemotherapy $[11,14,19]$. This simplification has supported increased patient access and higher adherence for pegfilgrastim over non-pegylated filgrastim $[14,20]$.

This Phase I/II ascending-dose study was designed to assess the pharmacodynamics (PD), pharmacokinetics (PK), and safety (including immunogenicity) of PF-06881894 (Fig. 1), in development as a biosimilar to reference product Neulasta ${ }^{\circledR}$. Each study phase (Phase I, Cycle 0; Phase II, Cycles 1-4) consisted of two independent study populations, differentiated by timing of PF-06881894 administration. Subjects in Phase I received PF-06881894 without chemotherapy and prior to definitive breast cancer surgery, whereas those in Phase II received PF-06881894 and concomitant adjuvant chemotherapy after definitive surgery. The study reported here was designed to assess 12 patients who received multiple 6-mg subcutaneous (SC) doses of
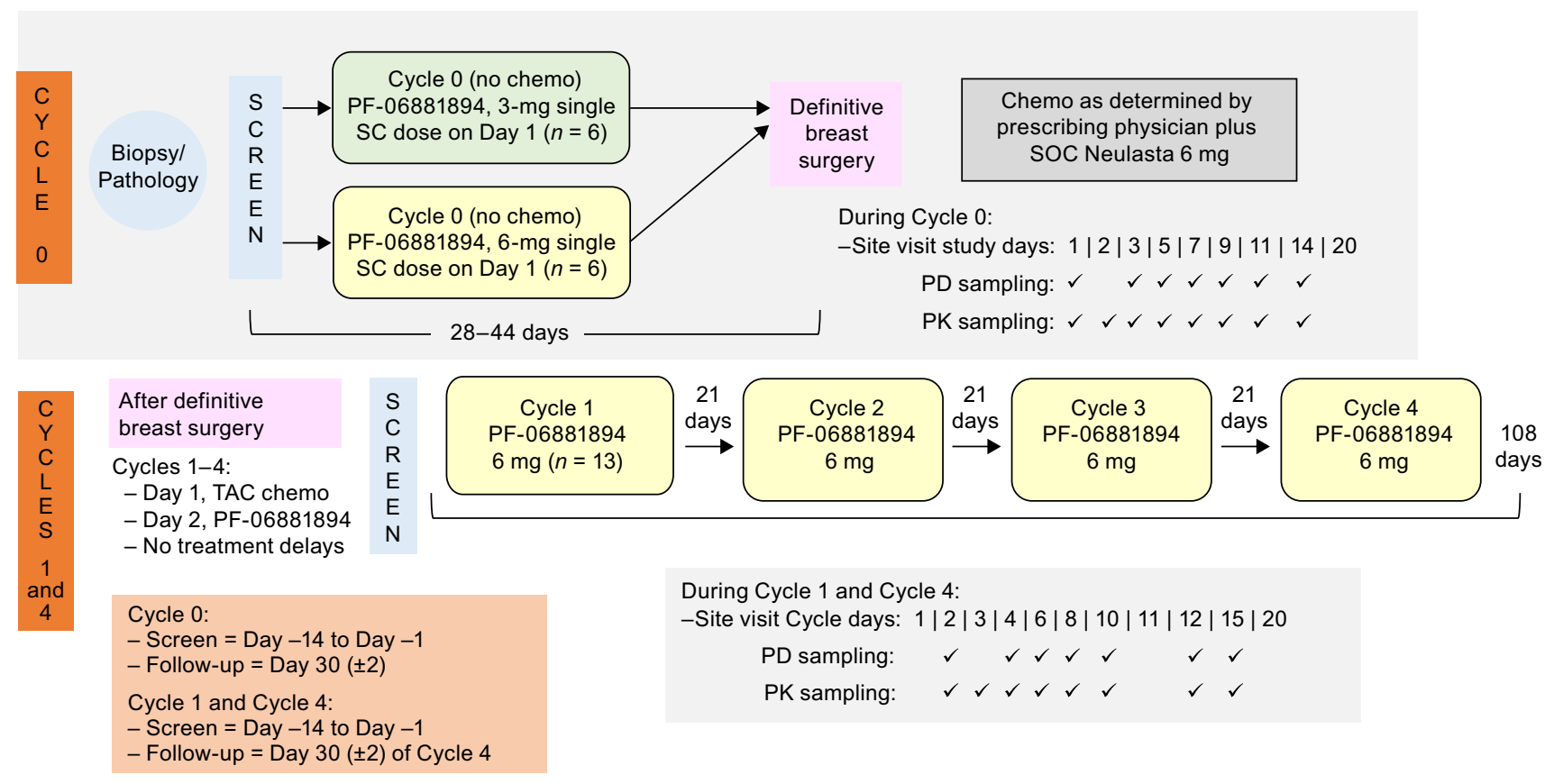

- Day 2, PF-06881894

- No treatment delays

During Cycle 1 and Cycle 4:

-Site visit Cycle days: 1 | 2 | 3 | 4 | 6 | 8 | 10 | 11 | 12 | 15 | 20

PD sampling:

$\checkmark \quad \checkmark \checkmark \checkmark \checkmark r \quad \checkmark \quad \checkmark$

PK sampling: $\quad \checkmark \checkmark \checkmark \checkmark \checkmark \checkmark \checkmark \checkmark \checkmark \checkmark$

Fig. 1 Study design. Chemo, chemotherapy; PD, pharmacodynamics; PK, pharmacokinetics; SC, subcutaneous; SOC, standard-of-care; TAC, docetaxel, doxorubicin and cyclophosphamide chemotherapy 
PF-06881894 (Cycles 1-4). The 6-mg dose was based on the approved dosage for the reference drug, Neulasta.

\section{Materials and methods}

\section{Study design}

Study C1221002 was a two-phase, open-label, non-comparative, parallel-group study (Phase I, Cycle 0 and Phase II, Cycles 1-4, each with independent populations). The study was conducted across several European sites (Hungary and Spain) in women with non-distantly metastatic (non-stage IV) breast cancer. Cycle 0 was conducted without chemotherapy, before patients underwent definitive cancer surgery. Cycles 1-4 were conducted after definitive cancer surgery and included treatment with concomitant adjuvant chemotherapy (Fig. 1).

The primary objective of Cycle 0 was to characterize the PD response to a single 3- or 6-mg SC dose of PF-06881894 in chemotherapy-naïve women with non-distantly metastatic breast cancer. The PD variables, absolute neutrophil count (ANC) and $\mathrm{CD} 34^{+}$count, were used to determine whether it would be appropriate to study multiple doses of $3 \mathrm{mg}$ in the context of background chemotherapy. Secondary objectives during Cycle 0 were to characterize the PK and safety profile of a single 3- or 6-mg SC dose.

The primary objective of Cycle 1 was to characterize the PD response of duration of severe Grade 4 neutropenia (DSN) to PF-06881894 when administered as single or multiple SC doses. Secondary objectives were to characterize the PD response (ANC) and PK profile of PF-06881894 in Cycles 1 and 4 when administered as single or multiple 6-mg SC doses, and to characterize the safety (including immunogenicity) of PF-06881894 when administered as single or multiple SC doses during Cycles 1-4.

This study was conducted in compliance with the protocol (ClinicalTrials.gov, NCT02650193; EudraCT Number: 2015-002057-35); the ethical principles originating in or derived from the 1964 Declaration of Helsinki; and in accordance with all International Council for Harmonisation Good Clinical Practice Guidelines. The final protocol, any amendments, and informed consent documentation were reviewed and approved by the Independent Ethics Committees at each site participating in the study. The original protocol was amended twice (July and December 2015) [21].

\section{Treatments}

\section{Cycle 0}

Cycle 0 assessed a single 3- or 6-mg SC dose of PF-06881894 after diagnostic biopsy and prior to definitive breast surgery and without concomitant or background chemotherapy. The period post-biopsy and pre-definitive surgery was generally limited to $\leq 44$ days. This timeframe was based on a maximum of 14 days for screening, 20 days for study assessments, and day 30 ( \pm 2 days) for a follow-up visit. A longer time period was allowed if needed.

A 14-day screening period was used to determine the eligibility of six patients for enrollment in the PF-06881894 single 3-mg dose cohort in Cycle 0. After a comprehensive safety assessment of these six evaluable patients revealed no contraindications for dose-escalation, six additional patients were sequentially screened for enrollment. A single 6-mg dose of PF-06881894 was administered on day 1. By day $30( \pm 2)$, each patient completed the subsequent visits for PD, PK, and safety (including anti-drug antibodies [ADAs]) assessments before ending their participation in the study.

In Cycle 0, both 3- and 6-mg doses demonstrated a neutrophil response consistent with published weight-based dosing data for Neulasta; as expected, the 3-mg dose demonstrated lower PD and PK results than the 6-mg dose, and therefore, 3-mg was not initiated in Cycles 1-4.

After Cycle 0 was completed, a separate study cohort (Cycles 1-4) was enrolled to receive multiple 6-mg SC doses of PF-06881894.

\section{Cycles 1-4}

Cycles 1-4 of docetaxel, doxorubicin, and cyclophosphamide (TAC) chemotherapy started after definitive breast surgery, according to standard of local practice. Patients received a 6-mg SC dose of PF-06881894 on day 2 (at least $24 \mathrm{~h}$ after chemotherapy) of four consecutive 21-day cycles of myelosuppressive TAC chemotherapy delivered on day 1 of each cycle.

\section{Study population}

Eligible patients included women $\geq 18$ years old with histologically confirmed and documented invasive breast cancer without evidence of distant metastases (non-Stage IV). Patients had body mass index (BMI) $19-40 \mathrm{~kg} / \mathrm{m}^{2}$; Eastern Cooperative Oncology Group performance status $\leq 2$ at screening; adequate bone marrow, hepatic and renal function reserve; were candidates for adjuvant chemotherapy with a TAC-based regimen; and chemotherapy-naïve. Main exclusion criteria included: known human epidermal growth factor receptor 2-positive or triple-negative breast cancer; any malignancy other than breast cancer (except adequately treated squamous or basal cell carcinoma of the skin, or cervical carcinoma in situ) within 5 years of the study; chemotherapy other than that included in this study; neoadjuvant chemotherapy or radiation therapy within 4 weeks; prior bone marrow or stem cell transplantation; malignancy 
within 5 years; known sickle cell disease; severe persistent drug-induced myelosuppression; active infection; known hypersensitivity to docetaxel, polysorbate 80 , or doxorubicin; and/or previous exposure to a G-CSF or a biosimilar G-CSF. Medically necessary medications taken at the time of study entry or throughout the study were permitted, with recommendation to exclude patients who received inhibitors and inducers of cytochrome P450 3A4 or 2D6 and/or P-glycoprotein or doxorubicin or trastuzumab, consistent with reference drug product prescribing recommendations. A complete list of inclusion and exclusion criteria is in the protocol [21].

\section{Primary and secondary PD and PK endpoints}

\section{Cycle 0}

During Cycle 0, the primary endpoint was the PD measurement of area under the effect versus time curve (AUEC) for ANC, from the time of dose administration to $288 \mathrm{~h}$ after dose administration ( AUEC $_{\mathrm{ANC}}$ ). Secondary PD variables were maximum effect for ANC ( $\left.\mathrm{ANC} \_E_{\max }\right)$; time of maximum effect for ANC ( ANC $\left._{-T \max }\right)$; AUEC for $\mathrm{CD}_{4} 4^{+}\left(\mathrm{AUEC}_{\mathrm{CD} 34^{+}}\right)$; maximum effect for $\mathrm{CD} 34^{+}$ count $\left(\mathrm{CD} 34^{+}{ }_{-} \mathrm{E}_{\max }\right)$; time of maximum effect for $\mathrm{CD} 34^{+}$ count $\left(\mathrm{CD} 34^{+} T_{\max }\right)$; $\mathrm{AUEC}_{\mathrm{ANC}}$ from zero to infinity $\left(\mathrm{AUEC}_{\mathrm{ANCinf}}\right)$; and $\mathrm{AUEC}_{\mathrm{CD} 34^{+}}$from zero to infinity $\left(\mathrm{AUEC}_{\mathrm{CD} 34^{+} \mathrm{inf}}\right)$.

Cycle 0 primary PK variables were area under the serum pegfilgrastim versus time curve (AUC) from time zero to time infinity $\left(\mathrm{AUC}_{\text {inf }}\right)$ and the maximum observed pegfilgrastim concentration $\left(C_{\max }\right)$ in Cycle 0 . Secondary PK variables were AUC to time of last measurable concentration $\left(\mathrm{AUC}_{\mathrm{t}}\right)$; time to maximum serum concentration $\left(T_{\max }\right)$; elimination half-life $\left(\mathrm{t}_{1 / 2}\right)$; elimination rate constant $(\lambda \mathrm{z})$; and apparent clearance $(\mathrm{CL} / \mathrm{F})$.

\section{Cycles 1-4}

The primary PD parameter was DSN, i.e., days with Grade 4 neutropenia ANC $<0.5 \times 10^{9} / \mathrm{L}$ in Cycle 1 . Secondary PD variables were: DSN in Cycle 4; ANC nadir; time of nadir; $\mathrm{AUEC}$; $\mathrm{AUEC}_{\mathrm{ANCinf}}$; incidence of febrile neutropenia (i.e., tympanic or axillary body temperature $>38.5^{\circ} \mathrm{C}$ for $>1 \mathrm{~h}$ with ANC $<1.0 \times 10^{9} / \mathrm{L}$ ); incidence of severe Grade 4 neutropenia; and time to ANC recovery (the first day with ANC $\geq 2.0 \times 10^{9} / \mathrm{L}$ after any day with ANC $<2.0 \times 10^{9} / \mathrm{L}$ ) in Cycles 1 and 4 . Additional PD parameters were $\mathrm{ANC} \_E_{\max }$ and ANC_ $T_{\max }$ in Cycle 1 and Cycle 4.

Primary PK variables were $\mathrm{AUC}_{\mathrm{t}}$ and $C_{\max }$ in Cycles 1 and 4 . Secondary variables were $\mathrm{AUC}_{\mathrm{inf}} ; T_{\max } ; t_{1 / 2} ; \lambda \mathrm{z}$; and $\mathrm{CL} / \mathrm{F}$ in Cycles 1 and 4.

\section{Other prespecified endpoints}

Safety assessments included the number of patients with treatment-emergent adverse events (TEAEs), serious AEs (SAEs) and AEs of special interest (AESI), and clinical laboratory abnormalities, as well as vital signs, 12-lead electrocardiogram (ECG), and/or physical examination abnormalities of clinical significance.

All medications taken within 7 days or five half-lives of screening (whichever was longer) were documented. Exposure to concomitant medication used during the study and immunogenicity (positive anti-pegfilgrastim and antipolyethylene glycol [anti-PEG] antibody status) were also documented.

\section{PD and PK assessments}

For the PD analysis during Cycle 0 , blood samples were collected for ANC and CD34 ${ }^{+}$count, within $1 \mathrm{~h}$ prior to dose administration on Day 1 Cycle 0 and at 48, 96, 144, 192,240 , and $312 \mathrm{~h}$ postdose. ANC samples were tested at a central clinical laboratory. Flow cytometry was used for the $\mathrm{CD} 34^{+}$count.

For the PK analysis during Cycle 0, blood samples were collected within $1 \mathrm{~h}$ prior to dose administration on day 1 and at $6,12,24,48,96,144,192,240$, and $312 \mathrm{~h}$ postdose. Validated enzyme-linked immunosorbent assay (ELISA) methodology was used to determine serum pegylated filgrastim concentrations using a double-antibody sandwich method with quantitation by absorbance (range, $100-5000 \mathrm{pg} / \mathrm{mL}$ ) [22, 23].

During Cycles 1-4, the same timepoints for PD (ANC only) and PK blood sample collection and methodologies applied as for Cycle 0 for like parameters, except that collections started on day 2 of chemotherapy in Cycles 1 and 4 only. PD and PK parameters were calculated using Phoenix WinNonlin (v6.4) non-compartmental analysis.

\section{Safety evaluations}

All patients who received at least one dose of PF-06881894 were included in the safety population. AEs were reported from the time of informed consent up to and including the follow-up visit (day $30 \pm 2$ ) in Cycles 0 and 4 (depending on study phase) or early discontinuation. AEs were coded using Medical Dictionary for Regulatory Activities v20.1, and causality was determined by investigator assessment. When the relationship of an AE to PF-06881894 was unavailable, it was assumed to be PF-06881894-related. 
AESIs were prospectively defined according to the US and EU product labels for pegfilgrastim reference Neulasta $[15,24]$.

Blood samples were collected to assess hematology (a complete blood count with platelets) and clinical chemistry (to evaluate organ function, diseases and/or disorders; and immunogenicity). During Cycle 0, sample collection for these assessments was at screening, during the treatment period (hematology: days 3, 7, 14, and 20; clinical chemistry: days $3,7,11$, and 20) and at the follow-up visit (day $30 \pm 2$ ). During Cycles 1 and 4, samples were collected at screening, during the treatment period (hematology: days $3,6,10,11,12,15$, and 20; clinical chemistry: days 3,6 , 10, 11, 12, and 20), and after Cycle 4 at the follow-up visit (Day $30 \pm 2$ ) or upon patient discontinuation. In addition, for Cycles 2 and 3, samples were to be obtained for hematology on days $3,6,10,11,12,15$, and 20 .

Urinalysis was performed at screening and at the Cycle 0 and Cycle 4 final follow-up visits. Investigators assessed any abnormalities for clinical significance. Independent of investigator assessment of abnormalities, all laboratory findings were subsequently graded according to the Common Terminology Criteria for Adverse Events v4.03.

A physical examination and a 12-lead resting ECG were performed at screening and after dosing at the Cycle 0 and Cycle 4 final follow-up visits. Changes over time were summarized by cycle within dose cohorts. Vital signs were monitored at screening, at every visit within cycles and at the Cycle 0 and Cycle 4 follow-up visits, or upon patient's discontinuation.

\section{Immunogenicity}

Blood samples were collected to test for anti-pegfilgrastim antibodies and anti-PEG antibodies during Cycle 0 on day 1 prior to dosing, and on days 14 and 20. ADA testing occurred on day 2 prior to dosing, and on day 20 of Cycles 1 and 4.

The methodology for antibody detection (Online Resource Methods S1) has been described previously by Moosavi et al. [25].

\section{Data analysis}

The anticipated overall study population was 24 patients ( $n \sim 12$ per study phase). PD and PK values were summarized by treatment cycle within dose cohorts using descriptive statistics for two populations: the full analysis set (FAS) and FAS excluding participants who were confirmed positive for anti-pegfilgrastim antibodies.

Safety data were summarized for the safety population for Cycle 0 and Cycles 1-4 within dose cohorts using descriptive statistics. AEs were listed for patients with a positive antipegfilgrastim antibody test and/or a positive anti-PEG test.

\section{Results}

\section{Patient disposition}

This Phase I/II study was conducted at ten sites (three sites in Hungary and seven in Spain) between 21 December 2015 and 5 October 2017. Three sites in Spain received study drug, but did not enroll patients.

Among the 31 patients screened for study participation, $25(80.6 \%)$ were enrolled in the study and $6(19.4 \%)$ were screen failures. During Cycle 0,12 patients received a single dose of PF-06881894 (3- or 6-mg; $n=6 /$ dose level).

During Cycles 1-4, 13 patients received multiple doses of PF-06881894 (6 mg per cycle). The 3-mg dose was not tested beyond Cycle 0 (as prespecified by study protocol). All enrolled patients across all cycles completed their respective study phase. The FAS, as well as the PD, PK, and safety populations, comprised 25 patients. No patients tested positive for anti-pegfilgrastim antibodies at any time point; there was no need to report on adjusted analysis sets with excluded patients.

Demographic and baseline characteristics for the FAS are summarized in Online Resource Table S1. The mean age at enrollment was 59 years, $96 \%$ of patients were White, with mean BMI of $30.6 \mathrm{~kg} / \mathrm{m}^{2}$. At least one medical condition was reported for all 25 patients, with no clinically meaningful differences between Cycle 0 and Cycles 1-4.

\section{Prior/concomitant medications}

All but one (8.3\%) patient in Cycle 0 (3-mg cohort) had received prior medication; the most common were angiotensin-converting-enzyme (ACE) inhibitors, acetylsalicylic acid, and/or benzodiazepine derivatives. The most commonly used concomitant medications during Cycle 0 included benzodiazepine derivatives and ACE inhibitors.

During Cycles 1-4, prior use of one or more of the most commonly used medications (by $>50 \%$ of patients for each drug) included glucocorticoids, serotonin antagonists, H2-receptor antagonists, and chloropyramine (the latter administered for management of chemotherapy side effects prior to receiving PF-06881894). The most common concomitant medications during Cycles 1-4 were the same as those used prior to Cycles 1-4. Each of these medications was used by $\geq 70 \%$ of patients. 
Fig. 2 Pharmacological effects of a single ascending-dose of $\mathrm{PF}-06881894$ over time in the absence of chemotherapy in Cycle 0. a ANC levels (FAS), b $\mathrm{CD}^{+} 4^{+}$(FAS), and $\mathbf{c}$ pegfilgrastim concentration ( $\mathrm{PK}$ population). ANC, absolute neutrophil count; FAS, full analysis set; PK, pharmacokinetics a

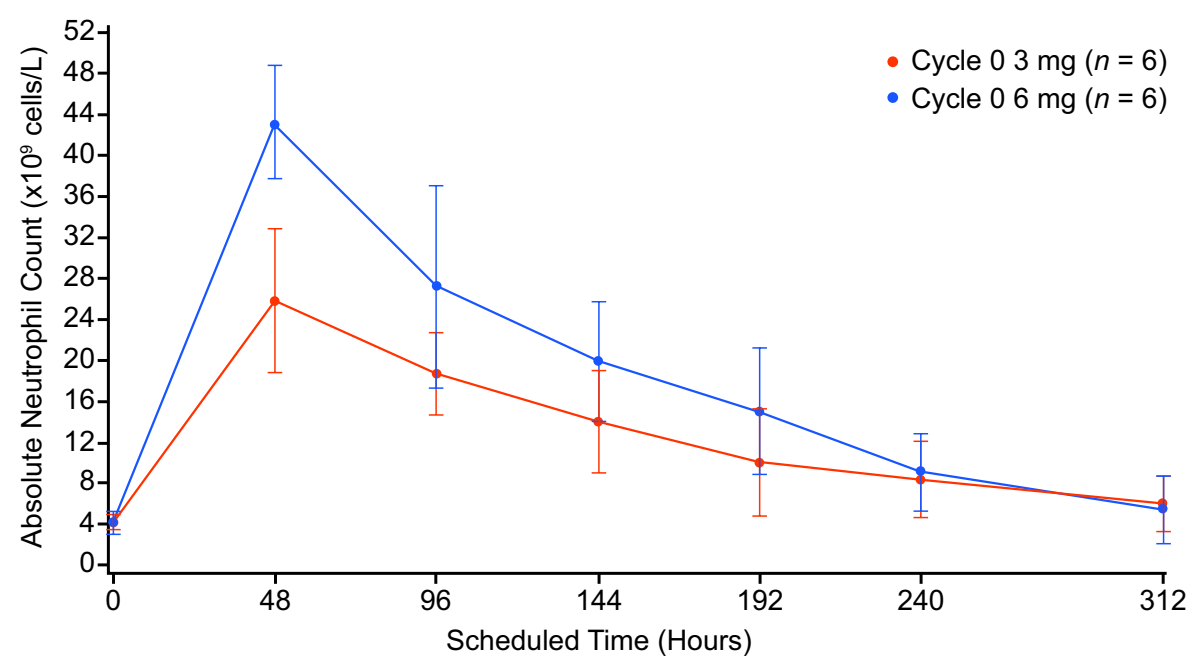

b

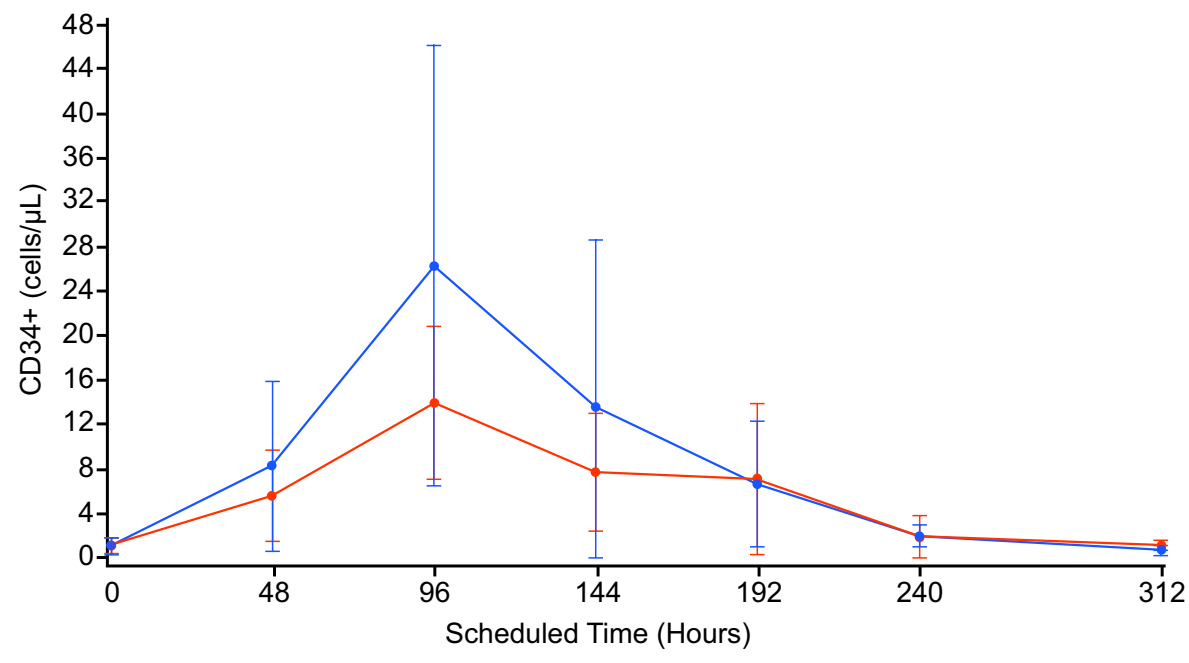

C

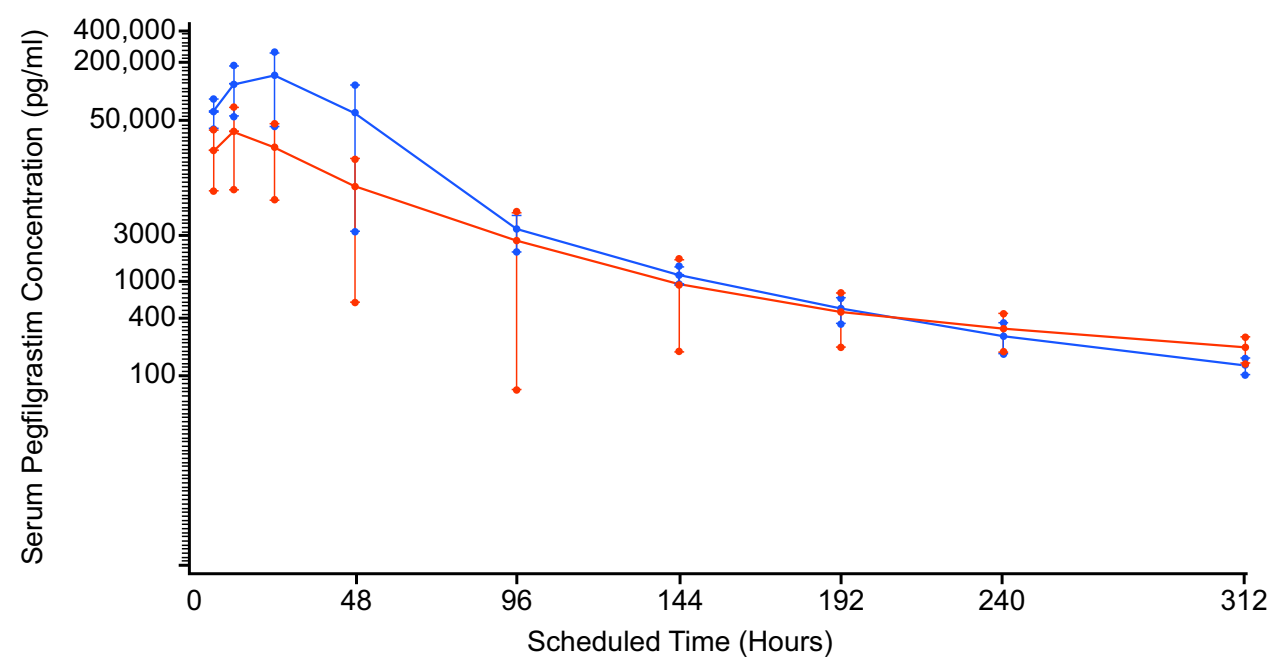


Table 1 Summary of the pharmacological parameters in the single ascending-dose Cycle 0 (full analysis set)

\begin{tabular}{|c|c|c|}
\hline \multirow[t]{2}{*}{ Parameters } & \multicolumn{2}{|l|}{ PF-06881894 ${ }^{\mathrm{a}}$} \\
\hline & $3 \mathrm{mg}$ & $6 \mathrm{mg}$ \\
\hline Subjects, $n$ & 6 & 6 \\
\hline \multicolumn{3}{|c|}{ Pharmacodynamics (ANC and $\left.\mathrm{CD} 34^{+}\right)$} \\
\hline $\mathrm{AUEC}_{\mathrm{ANC}}\left(\mathrm{h} \times 10^{9} / \mathrm{L}\right)^{\mathrm{b}}$ & $3900.482(683.6870)$ & $5880.985(1287.2887)$ \\
\hline $\mathrm{ANC} \_E_{\max }\left(\times 10^{9} / \mathrm{L}\right)^{\mathrm{b}}$ & $24.512(6.0710)$ & $43.257(5.5683)$ \\
\hline ANC_ $T_{\max }(\mathrm{h})^{\mathrm{b}}$ & $71.95[48.00-144.10]$ & $47.80[46.90-48.30]$ \\
\hline $\mathrm{AUEC}_{\mathrm{CD} 34^{+}}(\mathrm{h} \times \text { cells } / \mu \mathrm{L})^{\mathrm{b}}$ & $1749.523(1022.3037)$ & $2752.198(2152.8794)$ \\
\hline $\mathrm{CD} 34^{+} E_{\max }(\text { cells } / \mu \mathrm{L})^{\mathrm{b}}$ & $13.970(6.8536)$ & $27.343(18.4805)$ \\
\hline $\mathrm{CD} 34^{+} T_{\max }(\mathrm{h})^{\mathrm{b}}$ & $96.00[48.00-96.10]$ & $96.60[95.80-191.30]$ \\
\hline $\operatorname{AUEC}_{\text {ANCinf }}\left(\mathrm{h} \times 10^{9} / \mathrm{L}\right)$ & $5254.288(1699.7088)^{\mathrm{c}}$ & 6576.165 (1821.9919) \\
\hline $\mathrm{AUEC}_{\mathrm{CD} 34^{+} \text {inf }}(\mathrm{h} \times$ cells $/ \mu \mathrm{L})$ & $1835.221(1036.6473)$ & $3159.470(2197.4774)^{\mathrm{c}}$ \\
\hline \multicolumn{3}{|c|}{ Pharmacokinetics (serum pegfilgrastim) } \\
\hline $\mathrm{AUC}_{\mathrm{t}}(\mathrm{h} \times \mathrm{pg} / \mathrm{mL})^{\mathrm{b}}$ & $1,410,202.6(948,443.5)$ & $5,677,700.3(3,756,049.2)$ \\
\hline$C_{\max }(\mathrm{pg} / \mathrm{mL})^{\mathrm{b}}$ & $38,026.7(28,821.7)$ & $155,766.7(99,051.8)$ \\
\hline $\mathrm{AUC}_{\mathrm{inf}}(\mathrm{h} \times \mathrm{pg} / \mathrm{mL})^{\mathrm{b}}$ & $1,425,862.2(949,518.8)$ & $5,689,476.1(3,757,035.5)$ \\
\hline$T_{\max }(\mathrm{h})$ & $12.0[12-12]$ & $23.5[6-24]$ \\
\hline$t_{1 / 2}(\mathrm{~h})^{\mathrm{b}}$ & $50.0(15.5)$ & $48.8(12.5)$ \\
\hline$\lambda \mathrm{z}(/ \mathrm{h})^{\mathrm{b}}$ & $0.015(0.0051)$ & $0.015(0.0041)$ \\
\hline $\mathrm{CL} / \mathrm{F}(\mathrm{mL} / \mathrm{h})^{\mathrm{b}}$ & $4235.6(4714.4)$ & $1655.9(1242.6)$ \\
\hline
\end{tabular}

${ }^{a}$ Data are mean ( \pm standard deviation) or median [range]

${ }^{\mathrm{b}}$ Three measurable values per subject, per parameter assessed, within a specific cohort or study cycle were needed for reliable calculation and inclusion in the results

${ }^{c} n=5$

$\lambda z$ elimination rate constant; $A N C$ absolute neutrophil count; $A N C_{-} E_{\max }$ maximum effect for ANC; $A N C_{-}$ $T_{\max }$ time of maximum effect for ANC; $A U E C_{A N C}$ area under the effect versus time curve for ANC from the time of dose administration to $288 \mathrm{~h}$ after dose administration; $A U C_{i n f}$ area under the serum pegfilgrastim versus time curve from the time of dose administration to time infinity; $A U C_{t}$ area under the serum pegfilgrastim versus time curve from the time of dose administration to the time of last measurable concentration; $A U E C_{A N C i n f}$ area under the effect versus time curve for ANC from the time of dose administration to time infinity; $A U E C_{C D 34^{+}}$area under the effect curve for $\mathrm{CD}_{34^{+}}$; $\mathrm{AUEC}_{\mathrm{CD} 34^{+} \text {inf }}$ area under the effect curve for $\mathrm{CD} 34^{+}$from the time of dose administration to time infinity; $C D 34^{+}{ }_{-} E_{\max }$ maximum effect for $\mathrm{CD} 34^{+}$ count; $C D 34^{+}{ }_{-} T_{\max }$ time of maximum effect for CD34 ${ }^{+}$count; $C L / F$ apparent clearance, $C_{\max }$ maximum observed serum pegfilgrastim concentration; $t_{l / 2}$ elimination half-life; $T_{\max }$ time to maximum serum pegfilgrastim concentration

\section{PD and PK}

\section{Cycle 0}

The mean ANC values and mean $\mathrm{CD} 34^{+}$count during the earlier time points assessed within Cycle 0 were consistently greater following the 6-mg dose than the 3-mg dose of PF-06881894 (Fig. 2a, b). The PK exposure parameters were also higher in the 6-mg versus 3-mg cohorts $\left(\mathrm{AUC}_{\mathrm{t}}[\mathrm{h} \times \mathrm{pg} / \mathrm{mL}]\right.$ mean $\pm \mathrm{SD}: 5,677,700.3 \pm 3,756,049.2$ versus $1,410,202.6 \pm 948,443.5$ for the $6-\mathrm{mg}$ versus 3 -mg dose, respectively and $\mathrm{C}_{\max }[\mathrm{pg} / \mathrm{mL}]$ mean $\pm \mathrm{SD}$ : $155,766.7 \pm 99,051.8$ versus $38,026.7 \pm 28,821.7$ for the 6-mg versus 3-mg dose, respectively [Table 1]). Mean serum pegfilgrastim concentrations are shown by cohort in Fig. 2c.

In the absence of myelosuppressive chemotherapy in Cycle 0, the 3-mg dose of PF-06881894 exhibited a less adequate and potentially subtherapeutic $\mathrm{PD}$ response relative to the 6-mg dose (lower AUEC $_{\mathrm{ANC}}$ $\left[\mathrm{h} \times 10^{9} / \mathrm{L}\right]$ mean $\pm \mathrm{SD}: 3900.482 \pm 683.6870$ versus $5880.985 \pm 1287.2887$ for the 3 -mg versus 6 - $\mathrm{mg}$ dose, respectively and/or $\mathrm{AUEC}_{\mathrm{CD} 34^{+}}[\mathrm{h} \times$ cells $/ \mu \mathrm{L}]$ mean $\pm \mathrm{SD}$ : $1749.523 \pm 1022.3037$ versus $2752.198 \pm 2152.8794$ for the 3-mg versus 6-mg dose, respectively [Table 1]). In addition, PK values were indicative of lower pegfilgrastim exposure at the $3-\mathrm{mg}$ dose which was subsequently not included in Cycles 1-4. 
Table 2 Summary of pharmacological parameters in the multiple-dose Cycle 1 and Cycle 4 (full analysis set)

\begin{tabular}{|c|c|c|}
\hline \multirow[t]{2}{*}{ Parameter } & \multicolumn{2}{|l|}{ PF-06881894, 6-mg dose } \\
\hline & Cycle 1 & Cycle 4 \\
\hline Subjects, $n$ & 13 & 13 \\
\hline \multicolumn{3}{|l|}{ Pharmacodynamics $^{\mathrm{a}}$} \\
\hline DSN (days) ${ }^{\mathrm{b}}$ & $0.667(0.9847)^{\mathrm{c}}$ & $0.667(0.9847)^{\mathrm{c}}$ \\
\hline ANC nadir $\left(\times 10^{9} / \mathrm{L}\right)$ & $1.132(1.1480)$ & $1.623(1.8364)$ \\
\hline Time of ANC nadir (h) & $129.231(23.0585)$ & $142.154(65.3323)$ \\
\hline $\mathrm{AUEC}_{\mathrm{ANCt}}\left(\mathrm{h} \times 10^{9} / \mathrm{L}\right)$ & $2540.285(854.2237)$ & $3186.542(1362.0079)$ \\
\hline $\operatorname{AUEC}_{\text {ANCinf }}\left(\mathrm{h} \times 10^{9} / \mathrm{L}\right)$ & $5636.963(1974.1635)^{\mathrm{d}}$ & $12,399.370(18,345.3366)^{\mathrm{e}}$ \\
\hline ANC_E $E_{\max }\left(\times 10^{9} / \mathrm{L}\right)^{\mathrm{g}}$ & $18.286(5.4720)$ & $31.566(12.3701)$ \\
\hline ANC_ $T_{\max }(\mathrm{h})^{\mathrm{g}}$ & $47.80[46.00-191.10]$ & $47.90[46.10-48.60]$ \\
\hline Time to ANC recovery (days) ${ }^{\mathrm{f}}$ & $2.615(1.7097)$ & $2.0(1.633)$ \\
\hline \multicolumn{3}{|c|}{ Pharmacokinetics (serum pegfilgrastim) ${ }^{\mathrm{a}}$} \\
\hline $\mathrm{AUC}_{\mathrm{t}}(\mathrm{h} \times \mathrm{pg} / \mathrm{mL})^{\mathrm{g}}$ & $10,084,193.7(14,047,222.7)$ & $6,017,621.6(5,920,395.4)$ \\
\hline$C_{\max }(\mathrm{pg} / \mathrm{mL})^{\mathrm{g}}$ & $118,130.8(119,028.6)$ & $95,200.0(93,544.1)$ \\
\hline $\mathrm{AUC}_{\text {inf }}(\mathrm{h} \times \mathrm{pg} / \mathrm{mL})^{\mathrm{g}}$ & $10,093,213.5(14,047,936.2)$ & $6,425,013.3(6,000,938.3)^{\mathrm{c}}$ \\
\hline$T_{\max }(\mathrm{h})$ & $24.1[12-48]$ & $23.5[6-142]$ \\
\hline$t_{1 / 2}(\mathrm{~h})^{\mathrm{g}}$ & $30.7(10.8)$ & $29.5(9.5)^{\mathrm{c}}$ \\
\hline$\lambda z(/ h)^{g}$ & $0.026(0.0099)$ & $0.025(0.0060)^{\mathrm{c}}$ \\
\hline $\mathrm{CL} / \mathrm{F}(\mathrm{mL} / \mathrm{h})^{\mathrm{g}}$ & $1326.8(1010.2)$ & $2342.8(2043.8)^{\mathrm{c}}$ \\
\hline
\end{tabular}

${ }^{a}$ Data are mean ( \pm standard deviation) or median [range]

${ }^{\mathrm{b}} \mathrm{DSN}$ represents the days with severe Grade 4 neutropenia $\left(\mathrm{ANC}<0.5 \times 10^{9} / \mathrm{L}\right.$ )

${ }^{\mathrm{c}} n=12$

${ }^{\mathrm{d}} n=8$

${ }^{\mathrm{e}} n=7$

${ }^{\mathrm{f}}$ Time to ANC recovery is the first day with $\mathrm{ANC} \geq 2.0 \times 10^{9} / \mathrm{L}$ after any day with ANC $<2.0 \times 10^{9} / \mathrm{L}$

${ }^{\mathrm{g}}$ Three measurable values per subject, per parameter assessed, within a specific cohort or study cycle were needed for reliable calculation and inclusion in the results

$\lambda z$ elimination rate constant, $A U C_{\text {inf }}$ area under the serum pegfilgrastim versus time curve from the time of dose administration to time infinity, $A N C$ absolute neutrophil count, $A N C_{-} E_{\max }$ maximum effect for ANC, $A N C_{-} T_{\max }$ time of maximum effect for ANC, $A U C_{t}$ area under the serum pegfilgrastim versus time curve from the time of dose administration to the time of last measurable concentration, $A U E C_{A N C i n f}$ area under the effect versus time curve for ANC from the time of dose administration to time infinity, $A U E C_{A N C t}$ area under the effect versus time curve for ANC from the time of dose administration to the time of last measurable concentration, $C L / F$ apparent clearance, $C_{\max }$ maximum observed serum pegfilgrastim concentration, $D S N$ duration of severe Grade 4 neutropenia, $t_{1 / 2}$ elimination half-life, $T_{\max }$ time to maximum serum pegfilgrastim concentration

\section{Cycles 1-4}

Severe Grade 4 neutropenia was observed in five (38.5\%) patients; four of the same patients from Cycle 1 contributed to the count in Cycle 4 (Table 2).

The mean DSN for Cycle 1 and Cycle 4 were exactly the same (0.667 days); however, the PD response in Cycle 4 was comparatively more robust than in Cycle 1, exhibiting a higher and later ANC nadir, and recovery was more rapid $\left(\mathrm{ANC}\right.$ nadir $\left[\times 10^{9} / \mathrm{L}\right]$ mean $\pm \mathrm{SD}: 1.623 \pm 1.8364$ versus $1.132 \pm 1.1480$ for Cycle 4 and 1, respectively, and time of nadir $[\mathrm{h}]$ mean $\pm \mathrm{SD}: 142.154 \pm 65.3323$ versus 129.231 \pm 23.0585 for Cycle 4 and 1, respectively [Table 2]).
ANC levels over time for Cycles 1 and 4 are shown in Fig. 3. The ANC response was particularly robust within the initial $96 \mathrm{~h}$ of dose administration. Mean AUC and $C_{\max }$ values were lower and CL/F values were higher in Cycle 4 versus Cycle $1\left(\mathrm{AUC}_{\mathrm{t}}[\mathrm{h} \times \mathrm{pg} /\right.$ $\mathrm{mL}]$ mean $\pm \mathrm{SD}: 6,017,621.6 \pm 5,920,395.4$ versus $10,084,193.7 \pm 14,047,222.7$ for the $6-\mathrm{mg}$ dose in Cycle 4 versus Cycle 1, respectively; $C_{\max }[\mathrm{pg} / \mathrm{mL}]$ mean $\pm \mathrm{SD}$ : $95,200.0 \pm 93,544.1$ versus $118,130.8 \pm 119,028.6$ for the 6-mg dose in Cycle 4 versus Cycle 1, respectively; and $\mathrm{CL} / \mathrm{F}[\mathrm{mL} / \mathrm{h}]$ mean $\pm \mathrm{SD}: 2342.8 \pm 2043.8$ versus $1326.8 \pm 1010.2$ for the 6-mg dose in Cycle 4 versus Cycle 1 , respectively [Table 2]). 
Fig. 3 Pharmacological effects of multiple doses of $\mathrm{PF}-06881894$ over time in the context of myelosuppressive chemotherapy in Cycles 1 and 4. a ANC levels (FAS) and b pegfilgrastim concentration (PK population). ANC, absolute neutrophil count; FAS, full analysis set; PK, pharmacokinetics a

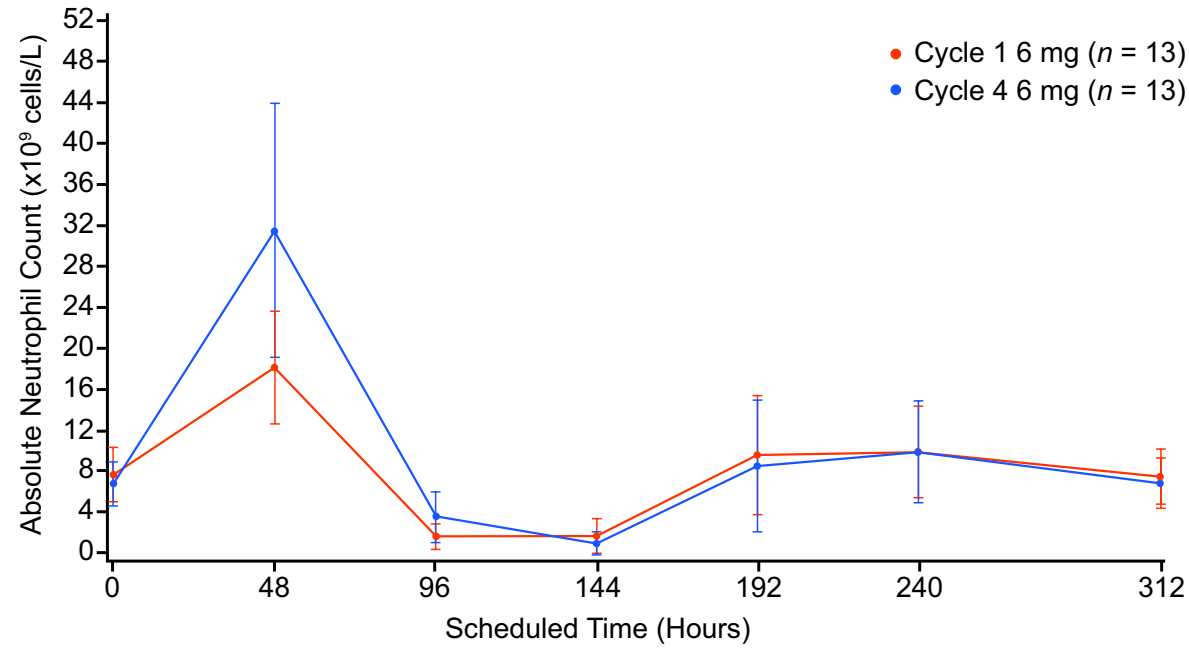

b

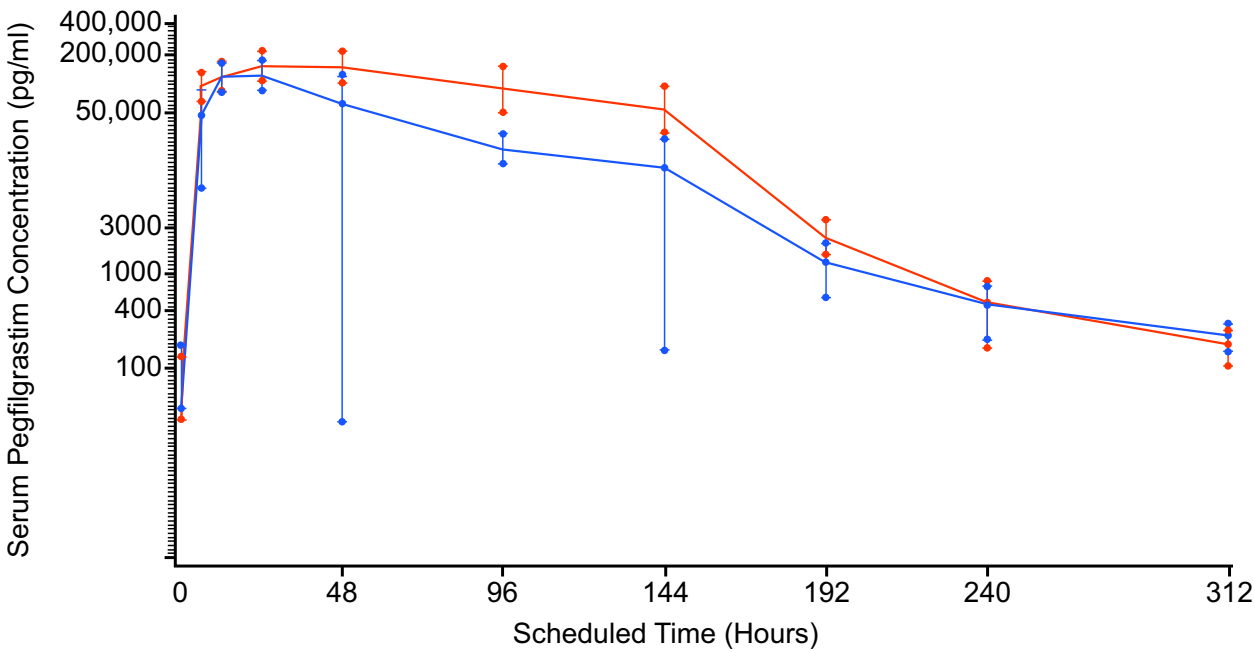

\section{Safety}

Overall, there were 161 (98.2\%) TEAEs reported during this Phase I/II study. No patients had a TEAE that led to discontinuation of PF-06881894 or discontinuation from the study, and no deaths were reported. There were no injection-site reactions (ISRs) reported during Cycle 0 or Cycles 1-4.

\section{Cycle 0}

During Cycle 0, without chemotherapy, a total of 46 TEAEs were reported for all $12(100 \%)$ patients, and the number of TEAEs was similar in the 3- and 6-mg single-dose cohorts (22 and 24 TEAEs, respectively) (Table 3). The most frequently reported TEAEs $(>2)$ were vertigo and backpain in the 3-mg dose cohort, and headache, backpain, and nausea in the 6-mg cohort. Most TEAEs of backpain and vertigo were treatment-related, and none were considered severe by the investigators (summarized in Online Resource Table S2). Two patients in the 6-mg PF-06881894 cohort experienced two events of dermatitis contact and leucocytosis (treatmentrelated), and both were mild in severity. No SAEs were reported during Cycle 0.

\section{Cycle 1-4}

During Cycles 1-4, a total of 115 TEAEs were reported among the 13 (100\%) women, each of whom had at least one moderate or severe TEAE. The most frequently reported TEAEs $(>5)$ were alopecia, nausea, and headache. The most frequently reported treatment-related TEAEs are summarized in Online Resource Table S2.

A total of three SAEs of febrile neutropenia, considered unrelated to PF-06881894, were reported for two patients. Each woman was hospitalized following TAC chemotherapy (one event in both Cycle 1 and 2 for a 48 -year-old patient; single event in Cycle 4 for a 64-year-old patient). These three events resolved with standard therapy (antibiotics, antipyretics). AESIs (three events: one face edema [of mild severity], two events of decreased platelet count in one patient) were 
Table 3 Summary of the most frequent treatment-emergent adverse events (reported in $>2$ subjects receiving any dose of PF-06881894 in either study phase per system organ class) in the safety population

\begin{tabular}{|c|c|c|c|}
\hline & \multicolumn{3}{|c|}{ PF-06881894 } \\
\hline & \multicolumn{2}{|c|}{$\begin{array}{l}\text { Cycle } 0 \\
\text { Single dose }\end{array}$} & \multirow{2}{*}{$\begin{array}{l}\text { Cycles 1-4 } \\
\text { Multiple doses } \\
6 \mathrm{mg}\end{array}$} \\
\hline & $3 \mathrm{mg}$ & $6 \mathrm{mg}$ & \\
\hline Subjects, $n$ & 6 & 6 & 13 \\
\hline Subjects who had TEAEs, $n(\%)$ & $6(100)$ & $6(100)$ & $13(100)$ \\
\hline No. of TEAEs & 22 & 24 & 115 \\
\hline Subjects who had treatment-related TEAEs, $n(\%)$ & $5(83.3)$ & $6(100)$ & $5(38.5)$ \\
\hline No. of treatment-related TEAEs & 11 & 12 & 12 \\
\hline Subjects who had treatment-emergent AESIs, $n(\%)$ & 0 & $2(33.3)^{\mathrm{a}}$ & $2(15.4)^{\mathrm{b}}$ \\
\hline No. of treatment-emergent AESIs & 0 & 2 & 3 \\
\hline Subjects who had a serious TEAE & 0 & 0 & $2(15.4)$ \\
\hline No. of serious TEAEs & 0 & 0 & $3^{\mathrm{c}}$ \\
\hline \multicolumn{4}{|c|}{ All-causality TEAEs by system organ class, preferred term, $n(\%)$} \\
\hline Blood and lymphatic system disorders & 0 & $1(16.7)$ & $4(30.8)$ \\
\hline Febrile neutropenia & - & - & $2(15.4)$ \\
\hline Leukocytosis & 0 & $1(16.7)$ & - \\
\hline Neutropenia & - & - & $1(7.7)$ \\
\hline Thrombocytosis & - & - & $1(7.7)$ \\
\hline Ear and labyrinth disorders & $2(33.3)$ & 0 & $1(7.7)$ \\
\hline Vertigo & $2(33.3)$ & 0 & $1(7.7)$ \\
\hline Gastrointestinal disorders & $2(33.3)$ & $3(50.0)$ & $11(84.6)$ \\
\hline Abdominal distension & $1(16.7)$ & 0 & - \\
\hline Abdominal pain & - & - & $1(7.7)$ \\
\hline Abdominal pain upper & - & - & $4(30.8)$ \\
\hline Aphthous ulcer & - & - & $2(15.4)$ \\
\hline Constipation & - & - & $1(7.7)$ \\
\hline Diarrhea & 0 & $1(16.7)$ & $4(30.8)$ \\
\hline Dry mouth & - & - & $1(7.7)$ \\
\hline Gingival pain & - & - & $1(7.7)$ \\
\hline Hyperchlorhydria & - & - & $1(7.7)$ \\
\hline Nausea & 0 & $2(33.3)$ & $7(53.8)$ \\
\hline Vomiting & $1(16.7)$ & 0 & $3(23.1)$ \\
\hline General disorders and administration-site conditions & $2(33.3)$ & 0 & $5(38.5)$ \\
\hline Asthenia & - & - & $2(15.4)$ \\
\hline Chest discomfort & $1(16.7)$ & 0 & - \\
\hline Chills & - & - & $1(7.7)$ \\
\hline Face edema & - & - & $1(7.7)$ \\
\hline Fatigue & - & - & $3(23.1)$ \\
\hline Inflammation & - & - & $1(7.7)$ \\
\hline Pain & $1(16.7)$ & 0 & - \\
\hline Pyrexia & - & - & $2(15.4)$ \\
\hline Infections and infestations & $1(16.7)$ & $1(16.7)$ & $3(23.1)$ \\
\hline Conjunctivitis & - & - & $2(15.4)$ \\
\hline Nasopharyngitis & 0 & $1(16.7)$ & - \\
\hline Skin infection & - & - & $1(7.7)$ \\
\hline Viral infection & $1(16.7)$ & 0 & - \\
\hline Musculoskeletal and connective tissue disorders & $4(66.7)$ & $3(50.0)$ & $8(61.5)$ \\
\hline Back pain & $2(33.3)$ & $2(33.3)$ & $4(30.8)$ \\
\hline Bone pain & - & - & $2(15.4)$ \\
\hline Myalgia & - & - & $3(23.1)$ \\
\hline
\end{tabular}


Table 3 (continued)

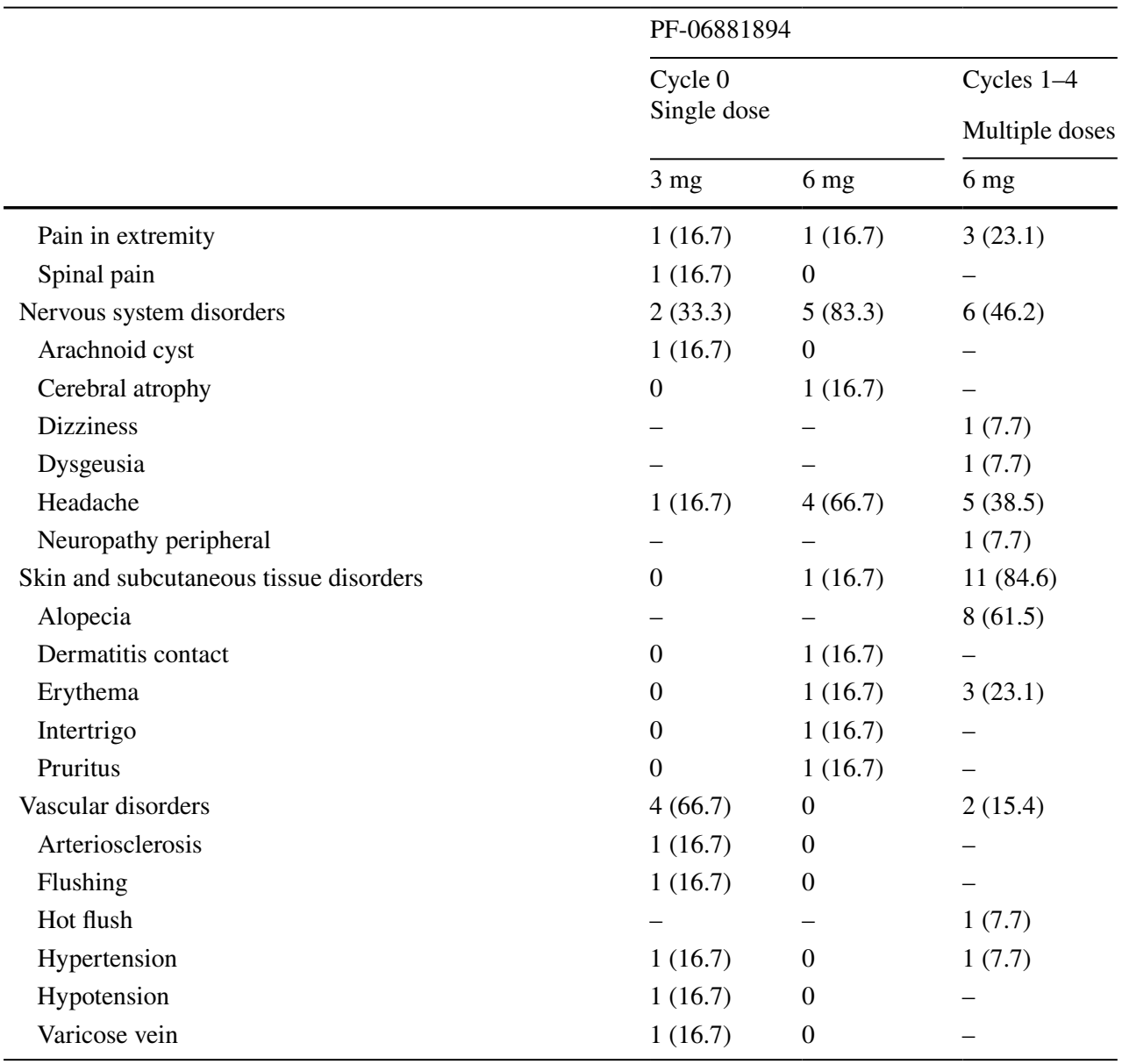

"Related" refers to any event that was assessed as either related or relationship is 'missing'

${ }^{a}$ Events were Dermatitis contact from the category of Potential Allergic Reactions ( 1 event), and leucocytosis considered related to PF-06881894 (1 event), both non-serious and mild in nature

${ }^{b}$ Events were face edema from the category of Potential Allergic Reactions (one event) in one subject, which was considered mild in severity and not related to PF-06881894. Another subject had platelet count decreased from the category of Thrombocytopenia (two events based on change in severity; the first severe, the second moderate), both of which were considered not related to PF-06881894

${ }^{c}$ Events were febrile neutropenia, considered unrelated to PF-06881894, which were reported for two (15.4\%) female subjects. Each woman was hospitalized following TAC chemotherapy (one event in both Cycle 1 and 2 for a 48-year-old subject; single event in Cycle 4 for a 64-year-old subject). These three events resolved with standard therapy (antibiotics and antipyretics)

$A E S I$ adverse event of special interest; TEAE treatment-emergent adverse event

reported in two patients, all were considered not related to treatment.

\section{Clinical laboratory results}

The clinical laboratory results and patterns observed were consistent with the known therapeutic response and safety profile for the US- and EU-approved pegfilgrastim (Neulasta). No patient in Cycle 0 or Cycles 1-4 had evidence of glomerulonephritis per urinalysis laboratory results. No changes in vital signs, ECG, and physical examination findings were considered clinically significant.

\section{Immunogenicity}

No patient tested for anti-pegfilgrastim antibodies was confirmed to be positive at any timepoint tested during Cycle 0 or Cycles 1 and 4 (Online Resource Table S3); therefore, no further characterization of the antibody response (e.g., neutralizing antibodies) was performed.

In contrast, anti-PEG antibodies were confirmed at one or more timepoints in all patients in the 3-mg dose group in Cycle 0 and none in Cycles 1 and 4. During Cycle 0, in the 3 -mg dose cohort, one patient (16.7\%) was anti-PEG-positive on day 1 prior to treatment. All six patients (100\%) in the same cohort were anti-PEG-positive on day 14 , and five 
(83.3\%) were positive on day 20. At each corresponding time point in Cycle 0, two (33.3\%) patients in the 6-mg singledose phase were confirmed positive for anti-PEG. None of the 13 patients in Cycles 1 or 4 tested positive for anti-PEG antibodies at any study time point assessed.

No ISRs or AEs considered related to immunogenicity were reported, regardless of positivity for anti-PEG. After receiving a 3-mg dose of PF-06881894, one of the eight subjects who tested positive for anti-PEG antibodies had a non-serious AE of flushing that was mild in severity, deemed not related to PF-06881894, resolved within $24 \mathrm{~h}$, and was considered to be attributable to a viral infection.

\section{Discussion}

In this Phase I/II ascending-dose study, the PD, PK, and safety of single and multiple SC doses of PF-06881894 were assessed in women with non-distantly metastatic breast cancer. Initial development of PF-06881894 occurred during the early days of biosimilar development in the US, with evolution of requirements by the FDA during the trial. The trial design was adaptive to determine if a true dose escalation $(3,6$, and $12 \mathrm{mg}$ ) would be required in the context of biosimilar development for the approved $6 \mathrm{mg}$ dosing of the reference product.

The FDA agreed that assessment of the PD/PK/safety of 3- and 6-mg doses in patients without concomitant immunosuppressive chemotherapy would address first-in-human use of PF-06881894, without placing patients at unnecessary risk for inadequate PD (ANC) response. Additionally, concern for potential leukocytosis $\left(>100 \times 10^{9} / \mathrm{L}\right)$ using a 12-mg dose led to a joint FDA-Sponsor decision regarding deferring of escalation to $12 \mathrm{mg}$ until after assessment of results of Phase I ( 3 or $6 \mathrm{mg}$ ) and Phase II $(6 \mathrm{mg}$ only, if $3 \mathrm{mg}$ was determined to be potentially subtherapeutic). After completion of all patients who received PF-06881894 in Cycle 0 it was agreed that it was appropriate not to study the 3-mg dose in patients receiving adjuvant chemotherapy, since that dose was deemed subtherapeutic relative to the 6-mg dose in Cycle 0 based on PD parameters. Additionally, it was jointly agreed with the FDA that escalation to the 12-mg dose would not be required to gain approval as a biosimilar.

When single-dose 3- or 6-mg PF-06881894 was administered to chemotherapy-naïve patients before definitive surgery (Phase I, Cycle 0), the neutrophil response was consistent with published, weight-adjusted dosing data for reference pegfilgrastim (Neulasta) [26], which indicated that both peak ANC level and duration of ANC response were dose-dependent.

The incidence of febrile neutropenia $(\sim 15 \%)$ observed in Cycles 1-4 is similar to other comparative studies of filgrastim biosimilars $[27,28]$. In one study, the number proportion of patients reporting at least one episode of febrile neutropenia was only $9 \%(n=12 / 139)$ for pegfilgrastim and $16 \%(n=21 / 134)$ for biosimilar filgrastim [27]. Similarly, another study reported 9 events $(n=153)$ and 13 events $(n=248)$ of febrile neutropenia in patients taking prophylactic filgrastim for 5 and $7 / 10$ days, respectively [28].

Based on the dose-response curve in patients with breast cancer [29], the average concentration $\left(C_{\mathrm{av}}\right)$ of pegfilgrastim (calculated from the time of administration to the time of ANC nadir) for the 6-mg dose was $72 \mathrm{ng} /$ $\mathrm{mL}$, which corresponds to $90 \%$ of maximum effective concentration $\left(\mathrm{EC}_{90}\right)$ response. For a 3-mg dose, the estimated $C_{\text {av }}$ was $\sim 21 \mathrm{ng} / \mathrm{mL}$, which corresponds to $\sim \mathrm{EC}_{70}$. The expected response for a $3-\mathrm{mg}$ dose $\left(\mathrm{EC}_{70}\right)$ is $77.8 \%$ of that from a 6-mg dose $\left(\mathrm{EC}_{90}\right)$. It is expected that $~ 30 \%$ of patients who received $3 \mathrm{mg}$ pegfilgrastim would have a $C_{\text {av }}$ value below the $\mathrm{EC}_{50}$ value. Therefore, a 3-mg dose of PF-06881894 may be potentially subtherapeutic in patients with breast cancer treated with myelosuppressive chemotherapy. The results in Cycle 0 confirmed the PD and PK of a 3-mg dose were less robust than those of a 6-mg dose. The lower systemic exposure to PF-06881894 in the 3-mg cohort is consistent with the lower ANC results (AUEC and $E_{\max }$ ) observed in this cohort. There were also differences in marrow response between the 3-mg and 6-mg cohorts based on the evidence provided by $\mathrm{CD} 34^{+}$counts. As a result of these findings and the safety risks of administration of a potentially subtherapeutic dose to patients receiving a chemotherapeutic regimen associated with clinically significant risk of myelosuppression and febrile neutropenia, the 3-mg dose was not included in Phase II (Cycles 1-4).

The DSN in patients receiving myelosuppressive chemotherapy is important in determining the risk for neutropenic fever and associated complications [30-32]. After recuperating from definitive surgery, the $\mathrm{PK}$ profile and $\mathrm{PD}$ response to a 6-mg/cycle regimen of PF-06881894 concomitant with chemotherapy were assessed during Cycles 1 and 4 to address any potential decrement in PD response over time. The observed PD response of $<1$ day for DSN during both Cycles 1 and 4 is consistent with that reported in the literature for reference pegfilgrastim $[33,34]$. The overall more robust PD response in Cycle 4 versus Cycle 1 of the Phase II study is also in line with reported data for reference pegfilgrastim [33, 34]. Liang et al. report that even with a larger difference of $\pm 40 \%$ in the ANC-AUEC between G-CSF products, the predicted mean difference in DSN between the products is still within \pm 1 day [35]. The same result is observed when we compare the ANC-AUEC and DSN in our study to those in Liang et al., the large difference of ANC-AUEC between two studies (our Cycle 1 
versus Liang et al.: 105 versus 71.6 or $\sim 105$ versus 70.5 ) is observed; however, the difference in DSN is still within 1 day ( 0.667 versus 1.1 day).

Neutrophil-mediated clearance is an important determinant of the physiologic response to pegfilgrastim [18, 33]. The higher ANC response (AUEC and $\mathrm{E}_{\max }$ ), the lower AUC and $C_{\max }$ and the higher $\mathrm{CL} / \mathrm{F}$ values of pegfilgrastim were observed in Cycle 4, when compared with corresponding values in Cycle 1. These are due to the neutrophil-mediated clearance of pegfilgrastim $[18,33]$ and higher ANC response in Cycle 4.

Anti-pegfilgrastim antibodies were not confirmed for any patient at any point during the Phase I/II study. Despite receiving multiple 6-mg doses of PF-06881894, patients in Cycles 1-4 did not exhibit an immunogenic response in terms of either anti-pegfilgrastim or anti-PEG.

Interestingly, anti-PEG antibodies were only confirmed among patients in Phase I, i.e., soon after cancer diagnosis and prior to any potentially immunosuppressive cancer therapy (definitive surgery or chemotherapy). The lack of anti-PEG antibodies in patients in Phase II may be related to these patients being more immunocompromised than patients in Phase I. Specifically, it is hypothesized that the lack of confirmed anti-PEG antibodies in the Phase II cohort is multifactorial and due to more time elapsing after their original cancer diagnosis combined with treatment with immunosuppressive cancer therapy including both definitive surgery and TAC chemotherapy.

The presence of anti-PEG antibodies in individuals who have not previously received a pegylated drug product is not unanticipated. It is well known that the prevalence of PEGylated polymers in a wide range of consumer products is a key reason why anti-PEG antibodies can be detected in $\sim 72 \%$ of the general population at any time and in some patients with cancer pre-treatment [36].

During the overall clinical development for PF-06881894 as a biosimilar, uses of multiple 6-mg doses were studied in healthy volunteers (NCT02629289) [25]. The observed immune response in the current study was considered consistent with the known ADA profile in these healthy volunteers, in terms of both anti-pegfilgrastim and anti-PEG responses.

Minimal effect of ADAs was observed on the PK/PD profile of PF-06881894. The presence of anti-PEG antibodies in all patients in the $3-\mathrm{mg}$ cohort in Cycle 0 precluded any assessment of their effect on PD or PK; however, it was noted that in the 6-mg cohort during Cycle 0, the two $(33.3 \%)$ of six subjects who were positive for anti-PEG antibodies had the highest AUEC $_{\mathrm{ANC}}$ and the lowest AUC, likely attributable to a higher neutrophil-mediated clearance as opposed to an effect of anti-PEG antibodies on PK.

The results for platelet counts were consistent with those for US- and EU-pegfilgrastim reference products. Results for PF-06881894 in healthy volunteers demonstrated return of counts to baseline levels by follow-up visit [25], and was also demonstrated in Phase II of this study. In addition, the observed clinical laboratory findings and safety profile were consistent with the known therapeutic response for the USand EU-approved pegfilgrastim reference product (Neulasta) $[25,37]$.

This trial was originally designed as a dose-finding study, but was transitioned by the Sponsor to a biosimilar regulatory pathway. The Phase I/II study provided supportive data in patients with breast cancer for biosimilar submission, as agreed in discussions with the FDA. Despite the inherent strengths of this unique adaptive study design, used to avert a subtherapeutic or supratherapeutic dosing regimen for patients, it also has some potential limitations. The study was non-comparative in nature; however, equivalent clinical efficacy and safety between pegfilgrastim reference products and pegfilgrastim biosimilars have been demonstrated in Phase I and II studies [25, 38, 39] in healthy volunteers [40] and cancer patients receiving chemotherapy [37, 41-46]. Another possible limitation of this study is the relatively small number of patients in the study population, which may lead to some interpretation bias of results. The target-mediated drug elimination could not be evaluated in this study.

\section{Conclusions}

The safety and efficacy of a single 3-mg or 6-mg dose of PF-06881894 without chemotherapy or a 6-mg/cycle dose over multiple chemotherapy cycles was consistent with the known safety profile and therapeutic response of Neulasta. Immunogenicity did not influence safety, and, overall, no new safety concerns emerged.

In Cycle 0, in the absence of chemotherapy for the treatment of breast cancer, results showed that while PD response (ANC and $\mathrm{CD}_{3} 4^{+}$) to a 6 -mg dose of PF-06881894 was robust, the $3-\mathrm{mg}$ dose was potentially subtherapeutic.

The mean duration of chemotherapy-induced severe neutropenia (DSN) did not decline over time in women with breast cancer from Cycle 1 to Cycle 4 (assessed in Cycles 1 and 4). The DSN in Cycle 1 and Cycle 4 was consistent with that reported for pegfilgrastim in the literature.

Supplementary Information The online version contains supplementary material available at https://doi.org/10.1007/s00280-021-04355-6.

Acknowledgements The authors thank the patients and their families, as well as all study investigators, research coordinators, and site staff. The authors also thank Enikô Varga for her contribution to the study. Medical writing support was provided by Sue Reinwald, $\mathrm{PhD}$, and Sharmy Blows, PhD, of Engage Scientific Solutions and was funded by Pfizer. 
Author contributions Conceptualization: FDO, HMY, and JZ. Methodology: FDO, HMY, and JZ. Data analysis: FDO, AF, SRJ, HMY, and JZ. Project administration: FDO. Writing-original draft: FDO, AF, SRJ, HMY, and JZ. Writing - review and editing: FDO, AF, SRJ, HMY, and JZ. Approval of final manuscript: all authors.

Funding Study C1221002 was funded by both Hospira Inc, which was acquired by Pfizer Inc in 2016, and by Pfizer.

Availability of data and materials Upon request, and subject to certain criteria, conditions, and exceptions (see https://www.pfizer.com/scien ce/clinical-trials/trial-data-and-results for more information), Pfizer will provide access to individual de-identified participant data from Pfizer-sponsored global interventional clinical studies conducted for medicines, vaccines, and medical devices: 1) for indications that have been approved in the USA and/or EU; or 2) in programs that have been terminated (i.e., development for all indications has been discontinued). Pfizer will also consider requests for the protocol, data dictionary, and statistical analysis plan. Data may be requested from Pfizer trials 24 months after study completion. The de-identified participant data will be made available to researchers whose proposals meet the research criteria and other conditions, and for which an exception does not apply, via a secure portal. To gain access, data requestors must enter into a data access agreement with Pfizer.

\section{Declarations}

Conflict of interest AF, SRJ, SM, H-MY, and JZ are full time employees of, and own stock or options, in Pfizer.

Ethics approval The final protocol, any amendments, and informed consent documentation were reviewed and approved by the Independent Ethics Committees at each site participating in the study. The original protocol was amended twice (in July and December 2015).

Open Access This article is licensed under a Creative Commons Attribution 4.0 International License, which permits use, sharing, adaptation, distribution and reproduction in any medium or format, as long as you give appropriate credit to the original author(s) and the source, provide a link to the Creative Commons licence, and indicate if changes were made. The images or other third party material in this article are included in the article's Creative Commons licence, unless indicated otherwise in a credit line to the material. If material is not included in the article's Creative Commons licence and your intended use is not permitted by statutory regulation or exceeds the permitted use, you will need to obtain permission directly from the copyright holder. To view a copy of this licence, visit http://creativecommons.org/licenses/by/4.0/.

\section{References}

1. Lucas AJ, Olin JL, Coleman MD (2018) Management and preventive measures for febrile neutropenia. P T 43(4):228-232

2. Wang L, Baser O, Kutikova L, Page JH, Barron R (2015) The impact of primary prophylaxis with granulocyte colony-stimulating factors on febrile neutropenia during chemotherapy: a systematic review and meta-analysis of randomized controlled trials. Support Care Cancer 23(11):3131-3140. https://doi.org/10.1007/ s00520-015-2686-9

3. Lyman GH, Dale DC, Culakova E, Poniewierski MS, Wolff DA, Kuderer NM, Huang M, Crawford J (2013) The impact of the granulocyte colony-stimulating factor on chemotherapy dose intensity and cancer survival: a systematic review and meta-analysis of randomized controlled trials. Ann Oncol: Off J Eur Soc Med Oncol 24(10):2475-2484. https://doi.org/10.1093/annonc/ mdt226

4. Chambers P, Jani Y, Wei L, Kipps E, Forster MD, Wong ICK (2019) Patient factors and their impact on neutropenic events: a systematic review and meta-analysis. Support Care Cancer 27(7):2413-2424. https://doi.org/10.1007/s00520-019-04773-6

5. Lyman GH, Dale DC, Legg JC, Abella E, Morrow PK, Whittaker S, Crawford J (2015) Assessing patients' risk of febrile neutropenia: is there a correlation between physician-assessed risk and model-predicted risk? Cancer Med 4(8):1153-1160. https://doi. org/10.1002/cam4.454

6. Smith TJ, Bohlke K, Lyman GH, Carson KR, Crawford J, Cross SJ, Goldberg JM, Khatcheressian JL, Leighl NB, Perkins CL, Somlo G, Wade JL, Wozniak AJ, Armitage JO, American Society of Clinical Oncology (2015) Recommendations for the use of WBC growth factors: American Society of Clinical Oncology clinical practice guideline update. J Clin Oncol 33(28):3199_ 3212. https://doi.org/10.1200/JCO.2015.62.3488

7. Becker PS, Griffiths EA, Alwan LM, Bachiashvili K, Brown A, Cool R, Curtin P, Dinner S, Gojo I, Hicks A, Kallam A, Kidwai WZ, Kloth DD, Kraut EH, Landsburg D, Lyman GH, Miller R, Mukherjee S, Patel S, Perez LE, Poust A, Rampal R, Rosovsky R, Roy V, Rugo HS, Shayani S, Vasu S, Wadleigh M, Westbrook K, Westervelt P, Burns J, Keller J, Pluchino LA (2020) NCCN guidelines insights: hematopoietic growth factors, version 1.2020. J Natl Compr Canc Netw 18(1):12-22. https://doi.org/10.6004/ jnccn.2020.0002

8. Shao L, Wang Y, Chang J, Luo Y, Meng A, Zhou D (2013) Hematopoietic stem cell senescence and cancer therapy-induced long-term bone marrow injury. Transl Cancer Res 2(5):397-411. https://doi.org/10.3978/j.issn.2218-676X.2013.07.03

9. Danova M, Antonuzzo A, Spandonaro F, Pronzato P (2020) Biosimilar pegfilgrastim and adherence to guidelines for chemotherapy-induced neutropenia and infections in cancer patients. Infez Med 28(1):127-129

10. National Comprehensive Cancer Network ${ }^{\circledR}(2020)$ NCCN Clinical Practice Guidelines in Oncology (NCCN Guidelines $\left.{ }^{\circledR}\right)$. Myeloid growth factors (version 1.2017). https://www.nccn.org/profe ssionals/physician_gls/default.aspx. Accessed 2 February 2021

11. Melhem M, Delor I, Perez-Ruixo JJ, Harrold J, Chow A, Wu L, Jacqmin P (2018) Pharmacokinetic-pharmacodynamic modelling of neutrophil response to G-CSF in healthy subjects and patients with chemotherapy-induced neutropenia. Br J Clin Pharmacol 84(5):911-925. https://doi.org/10.1111/bcp.13504

12. Lee J, Lee JE, Kim Z, Han SW, Hur SM, Kim SY, Lee MH, Lim CW (2018) Pegfilgrastim for primary prophylaxis of febrile neutropenia in breast cancer patients undergoing TAC chemotherapy. Ann Surg Treat Res 94(5):223-228. https://doi.org/10.4174/astr. 2018.94.5.223

13. Li Y, Klippel Z, Shih X, Wang H, Reiner M, Page JH (2016) Trajectory of absolute neutrophil counts in patients treated with pegfilgrastim on the day of chemotherapy versus the day after chemotherapy. Cancer Chemother Pharmacol 77(4):703-712. https://doi.org/10.1007/s00280-016-2970-5

14. Cornes P, Gascon P, Vulto AG, Aapro M (2020) Biosimilar pegfilgrastim: improving access and optimising practice to supportive care that enables cure. BioDrugs 34(3):255-263. https://doi.org/ 10.1007/s40259-020-00411-4

15. Amgen Inc. (2019) NEULASTA® (pegfilgrastim) prescribing infomation. https://www.accessdata.fda.gov/drugsatfda_docs/ label/2015/125031s180lbl.pdf. Accessed 2 February 2021 
16. Pfizer Inc. (2020) NYVEPRIA TM (pegfilgrastim-apgf) prescribing information. https://www.accessdata.fda.gov/drugsatfda_docs/ label/2020/761111lbl.pdf Accessed 2 February 2021

17. U.S. Food and Drug Administration (2015) Scientific considerations in demonstrating biosimilarity to a reference product. Guidance for industry. http://www.fda.gov/downloads/Drugs/Guida nceComplianceRegulatoryInformation/Guidances/UCM291128. pdf. Accessed 2 February 2021

18. Molineux G (2004) The design and development of pegfilgrastim (PEG-rmetHuG-CSF, Neulasta ${ }^{\circledR}$ ). Curr Pharm Des 10(11):12351244. https://doi.org/10.2174/1381612043452613

19. Crawford J (2003) Safety and efficacy of pegfilgrastim in patients receiving myelosuppressive chemotherapy. Pharmacotherapy $23(8$ Pt 2):15S-19S. https://doi.org/10.1592/phco.23.9.15s.32889

20. Aapro M, Boccia R, Leonard R, Camps C, Campone M, Choquet S, Danova M, Glaspy J, Hus I, Link H, Sliwa T, Tesch H, Valero V (2017) Refining the role of pegfilgrastim (a long-acting G-CSF) for prevention of chemotherapy-induced febrile neutropenia: consensus guidance recommendations. Support Care Cancer 25(11):3295-3304. https://doi.org/10.1007/s00520-017-3842-1

21. CLINICAL STUDY PROTOCOL (2015) ZIN-130-1504 A phase 1-2 ascending dose study to assess the pharmacodynamics, pharmacokinetics, and safety of HSP-130 in subjects with nonmetastatic breast cancer following single-dose and multiple-dose administration by subcutaneous injection. https://clinicaltrials. gov/ProvidedDocs/93/NCT02650193/Prot_000.pdf

22. U.S. Food and Drug Administration (2001) Guidance for Industry: Bioanalytical Method Validation, May 2001. U.S. Department of Health and Human Services, Food and Drug Administration, Center for Drug Evaluation and Research (CDER), Center for Veterinary Medicine (CMV). http://www.fda.gov/ downloads/drugs/guidancecomplianceregulatoryinformation/ guidances/ucm070107.pdf. Accessed 2 February 2021

23. U.S. Food and Drug Administration (2013) Guidance for industry: bioanalytical method validation,. September 2013. U.S. Department of Health and Human Services, Food and Drug Administration, Center for Drug Evaluation and Research (CDER), Center for Veterinary Medicine (CMV). https:// www.regulations.gov/document?D=FDA-2013-D-1020-0002. Accessed 2 February 2021

24. Amgen Ltd. (2018) NEULASTA® (pegfilgrastim) summary of product characteristics. https://www.medicines.org.uk/emc/ product/6770/smpc\#DOCREVISION. Accessed 2 February 2021

25. Moosavi S, Borema T, Ewesuedo R, Harris S, Levy J, May TB, Summers M, Thomas JS, Zhang J, Yao HM (2020) PF-06881894, a proposed biosimilar to pegfilgrastim, versus US-licensed and EU-approved pegfilgrastim reference products $\left(\right.$ Neulasta $\left.{ }^{\circledR}\right)$ : pharmacodynamics, pharmacokinetics, immunogenicity, and safety of single or multiple subcutaneous doses in healthy volunteers. Adv Ther 37(7):3370-3391. https://doi.org/ 10.1007/s12325-020-01387-x

26. Johnston E, Crawford J, Blackwell S, Bjurstrom T, Lockbaum P, Roskos L, Yang BB, Gardner S, Miller-Messana MA, Shoemaker D, Garst J, Schwab G (2000) Randomized, dose-escalation study of SD/01 compared with daily filgrastim in patients receiving chemotherapy. J Clin Oncol 18(13):2522-2528. https://doi.org/10.1200/JCO.2000.18.13.2522

27. Brito M, Esteves S, Andre R, Isidoro M, Moreira A (2016) Comparison of effectiveness of biosimilar filgrastim (Nivestim), reference Amgen filgrastim and pegfilgrastim in febrile neutropenia primary prevention in breast cancer patients treated with neo(adjuvant) TAC: a non-interventional cohort study. Support Care Cancer 24(2):597-603. https://doi.org/10.1007/ s00520-015-2818-2
28. Clemons M, Fergusson D, Simos D, Mates M, Robinson A, Califaretti N, Zibdawi L, Bahl M, Raphael J, Ibrahim MFK, Fernandes R, Pitre L, Aseyev O, Stober C, Vandermeer L, Saunders D, Hutton B, Mallick R, Pond GR, Awan A, Hilton J (2020) A multicentre, randomised trial comparing schedules of G-CSF (filgrastim) administration for primary prophylaxis of chemotherapy-induced febrile neutropenia in early stage breast cancer. Ann Oncol: Off J Eur Soc Med Oncol 31(7):951-957. https://doi.org/10.1016/j.annonc.2020.04.005

29. Yang BB, Kido A, Shibata A (2007) Serum pegfilgrastim concentrations during recovery of absolute neutrophil count in patients with cancer receiving pegfilgrastim after chemotherapy. Pharmacotherapy 27(10):1387-1393. https://doi.org/10.1592/ phco.27.10.1387

30. Cameron D (2009) Management of chemotherapy-associated febrile neutropenia. Br J Cancer 101(Suppl 1):18-22. https:// doi.org/10.1038/sj.bjc.6605272

31. Crawford J, Dale DC, Lyman GH (2004) Chemotherapy-induced neutropenia. Cancer 100(2):228-237. https://doi.org/10.1002/ cncr.11882

32. Moon JM, Chun BJ (2009) Predicting the complicated neutropenic fever in the emergency department. Emerg Med J 26(11):802-806. https://doi.org/10.1136/emj.2008.064865

33. Yang BB, Kido A (2011) Pharmacokinetics and pharmacodynamics of pegfilgrastim. Clin Pharmacokinet 50(5):295-306. https://doi.org/10.2165/11586040-000000000-00000

34. Yang BB, Savin MA, Green M (2012) Prevention of chemotherapy-induced neutropenia with pegfilgrastim: pharmacokinetics and patient outcomes. Chemotherapy 58(5):387-398. https:// doi.org/10.1159/000345626

35. Li L, Ma L, Schrieber SJ, Rahman NA, Deisseroth A, Farrell AT, Wang Y, Sinha V, Marathe A (2018) Quantitative relationship between AUEC of absolute neutrophil count and duration of severe neutropenia for G-CSF in breast cancer patients. Clin Pharmacol Ther 104(4):742-748. https://doi.org/10.1002/cpt. 991

36. Yang Q, Jacobs TM, McCallen JD, Moore DT, Huckaby JT, Edelstein JN, Lai SK (2016) Analysis of pre-existing IgG and IgM antibodies against polyethylene glycol (PEG) in the general population. Anal Chem 88(23):11804-11812. https://doi.org/10. 1021/acs.analchem.6b03437

37. Wang Y, Chen L, Liu F, Zhao N, Xu L, Fu B, Li Y (2019) Efficacy and tolerability of granulocyte colony-stimulating factors in cancer patients after chemotherapy: a systematic review and Bayesian network meta-analysis. Sci Rep 9(1):15374. https:// doi.org/10.1038/s41598-019-51982-4

38. Waller CF, Tiessen RG, Lawrence TE, Shaw A, Liu MS, Sharma R, Baczkowski M, Kothekar MA, Micales CE, Barve A, Ranganna GM, Pennella EJ (2018) A pharmacokinetics and pharmacodynamics equivalence trial of the proposed pegfilgrastim biosimilar, MYL-1401H, versus reference pegfilgrastim. J Cancer Res Clin Oncol 144(6):1087-1095. https://doi.org/10.1007/ s00432-018-2643-3

39. Harbeck N, Wang J, Otto GP, Gattu S, Krendyukov A (2019) Safety analysis of proposed pegfilgrastim biosimilar in phase I and phase III studies. Future Oncol 15(12):1313-1322. https:// doi.org/10.2217/fon-2018-0878

40. Bellon A, Wang J, Skerjanec A, Velinova M, Dickerson D, Sabet A, Ngo L, O'Reilly T, Tomek C, Schussler S, Schier-Mumzhiu S, Gattu S, Koch SD, Schelcher C, Dobreva M, Boldea A, Nakov R, Otto GP (2020) A large multicentre, randomized, double-blind, cross-over study in healthy volunteers to compare pharmacokinetics, pharmacodynamics and safety of a pegfilgrastim biosimilar with its US- and EU-reference biologics. $\mathrm{Br}$ J Clin Pharmacol 86(6):1139-1149. https://doi.org/10.1111/bcp. 14226 
41. Botteri E, Krendyukov A, Curigliano G (2018) Comparing granulocyte colony-stimulating factor filgrastim and pegfilgrastim to its biosimilars in terms of efficacy and safety: a meta-analysis of randomised clinical trials in breast cancer patients. Eur J Cancer 89:49-55. https://doi.org/10.1016/j.ejca.2017.10.034

42. Desai K, Misra P, Kher S, Shah N (2018) Clinical confirmation to demonstrate similarity for a biosimilar pegfilgrastim: a 3 -way randomized equivalence study for a proposed biosimilar pegfilgrastim versus US-licensed and EU-approved reference products in breast cancer patients receiving myelosuppressive chemotherapy. Exp Hematol Oncol 7:22. https://doi.org/10. 1186/s40164-018-0114-9

43. Kahan Z, Grecea D, Smakal M, Tjulandin S, Bondarenko I, Perjesi L, Illes A, Horvat-Karajz K, Aradi I (2019) Efficacy and safety of RGB-02, a pegfilgrastim biosimilar to prevent chemotherapy-induced neutropenia: results of a randomized, double-blind phase III clinical study vs. reference pegfilgrastim in patients with breast cancer receiving chemotherapy. BMC Cancer 19(1):122. https://doi.org/10.1186/s12885-019-5329-6

44. Kang KW, Lee BH, Jeon MJ, Yu ES, Kim DS, Lee SR, Sung HJ, Choi CW, Park Y, Kim BS (2020) Efficacy and safety of two pegfilgrastim biosimilars: tripegfilgrastim and pegteograstim. Cancer Med 9(17):6102-6110. https://doi.org/10.1002/cam4. 3261
45. Waller CF, Ranganna GM, Pennella EJ, Blakeley C, Bronchud MH, Mattano LA Jr, Berzoy O, Voitko N, Shparyk Y, Lytvyn I, Rusyn A, Popov V, Láng I, Beckmann K, Sharma R, Baczkowski M, Kothekar M, Barve A (2019) Randomized phase 3 efficacy and safety trial of proposed pegfilgrastim biosimilar MYL-1401H in the prophylactic treatment of chemotherapyinduced neutropenia. Ann Hematol 98(5):1217-1224. https:// doi.org/10.1007/s00277-019-03639-5

46. Zhou C, Huang Y, Wang D, An C, Zhou F, Li Y, Chen G, Wu C, He J, Wu G, Song X, Gao J, Liu W, Li B, Shi J, Huang C, Yu J, Feng J, Yue H, Shi M, Xia J (2016) A randomized multicenter phase iii study of single administration of mecapegfilgrastim (HHPG-19K), a pegfilgrastim biosimilar, for prophylaxis of chemotherapy-induced neutropenia in patients with advanced non-small-cell lung cancer (NSCLC). Clin Lung Cancer 17(2):119-127. https://doi.org/10.1016/j.cllc.2015.12.002

Publisher's Note Springer Nature remains neutral with regard to jurisdictional claims in published maps and institutional affiliations. 